ESTRATÉGIA 


\title{
ARTICULAÇÃO DE STAKEHOLDERS E ESTRATÉGIAS NO SETOR TURÍSTICO BRASILEIRO: UMA INVESTIGAÇÃO EM LOCALIDADES
}

\author{
STAKEHOLDERS ARTICULATION AND STRATEGIES IN THE BRAZILIAN TOURISM \\ SECTOR: A RESEARCH IN PLACES
}

Benny Kramer Costa

Universidade Nove de Julho

Saulo Fabiano Amâncio-Vieira

Universidade Estadual de Londrina

Mauro Lemuel de Oliveira Alexandre

Universidade Federal do Rio Grande do Norte
Viviane Celina Carmona

Universidade Nove de Julho
Data de submissão: 22 jun. 20|5. Data de aprovação:

10 dez. 2015. Sistema de avaliação: Double blind review.

Universidade FUMEC / FACE. Prof. Dr. Henrique Cordeiro

Martins. Prof. Dr. Cid Gonçalves Filho. Prof. Dr. Luiz Claudio

Vieira de Oliveira

\section{RESUMO}

O presente artigo visa a compreender de que forma se processa a inserção e o envolvimento dos stakeholders nas estratégias existentes na atividade do turismo. Para tanto, utilizou-se como referencial a teoria dos stakeholders. A partir da abordagem qualitativa, o trabalho realizado enquadra-se como sendo uma pesquisa do tipo exploratória e descritiva, utilizando-se o método de estudo de casos múltiplos. Conclui-se que o processo de desenvolvimento do turismo tem estreita relação com o papel dos diversos stakeholders, cuja perspectiva é necessária se compreender em prol do alcance do desenvolvimento, contemplando as dimensões econômica, social e ambiental e competitiva.

PALAVRAS-CHAVE

Estratégia. Formulação Estratégica. Stakeholder.Turismo. 


\section{ABSTRAT}

This article aims to understand how the inclusion and involvement of stakeholders happen in existing strategies in the tourism activity. Therefore, the theory of stakeholders was used as reference. In the qualitative approach, the study is an exploratory and descriptive survey that uses the method of study of multiple cases. We conclude that the process of tourism development is closely related to the role of the various stakeholders, whose perspective is necessary if it understands in favor of achieving development, addressing the economic, social, environmental and competitive dimensions.

KEYWORDS

Strategy. Strategic Formulation. Stakeholder. Tourism.

\section{INTRODUÇÃO}

A necessidade premente, dos países emergentes, de enveredar pelo caminho do desenvolvimento sustentável, tem induzido estados, regiões, municípios e organizações a realizarem importantes transformações, a fim de se adequarem a essa situação.

A busca desse bem-estar traz, em seu arcabouço, a exploração e o desenvolvimento de setores importantes da economia de qualquer nação. Dentre esses setores, no Brasil, pode ser destacado o do turismo que, nos últimos anos, vem enfrentando uma expansão acentuada. Ela se dá tanto no que diz respeito aos aspectos de oferta, com novas localidades se apresentando como destinos receptores, como pelo lado da demanda, com o aumento da propensão dos residentes a viajar e do fluxo internacional para o país.

No Brasil, têm-se realizado diversos estudos relacionados à atividade turística, porém obedecendo a uma lógica de fins e interesses mais específicos e correlacionando aspectos mais estruturais e sistêmicos. Entretanto, a abordagem de stakeholders, no estado da arte da estratégia organizacional, é mais apropriada e inova na sua maior aplicabilidade nos processos de tomada de decisão das organizações e oferece argumentação sólida e opção tangível em relação à definição, busca, monitoramento e alcance dos objetivos organizacionais.

Dessa forma, faz-se necessária a realização de um trabalho que congregue desejos e interesses das localidades receptoras, sobretudo relacionados a essa dinâmica e estratégica atividade do turismo, envolvendo o setor turístico em geral, o poder público local e os grupos organizados das localidades propriamente ditas. Esse envolvimento torna-se viável na medida em que as ideias e necessidades individuais e de grupos são contempladas e, a partir daí, são desenvolvidas suas inter-relações.

Também merecem ser enfatizados outros fatores relevantes, com a intenção de melhorar os níveis de conhecimento e conscientização do tema estratégia na atividade do turismo, de modo a fornecer um embasamento inicial para a criação de debates em diversas esferas no país e exte- 
rior. Soma-se a isso o clima nacional para a realização da Copa do Mundo de futebol, em 2014, e dos Jogos Olímpicos, em 2016, que têm exigido estudos prévios que visam a compreender realidades locais e instrumentalizar práticas de política e gestão.

Nesse contexto, merece ser frisada a importância da realização deste estudo, no sentido de estabelecer uma sistemática da análise dos stakeholders e da formulação de estratégias para o turismo nessas localidades, de modo a se criar um conjunto de impactos que foquem os aspectos empírico, metodológico e científico.

As organizações são caracterizadas por suas relações com vários grupos e indivíduos, qualificados como stakeholders, que dispõem de interesses legítimos, bem como têm o poder de afetar o seu desempenho (EVANS, 2003). Para Freeman (I984), os stakeholders, pelo ponto de vista da firma, correspondem aos seguintes atores: proprietários, defensores dos consumidores, consumidores, competidores, mídia, empregados, grupos de interesses especiais, ambientalistas, fornecedores, governantes e as organizações comunitárias locais.

Em relação aos aspectos teóricos, observa-se no cenário internacional, que têm sido desenvolvidos inúmeros estudos relacionados à análise dos stakeholders, formulação de estratégias e uso de estratégias, principalmente na esfera das organizações, contemplando, em muitas delas, aplicações nas mais diversas atividades econômicas. No que se refere ao estudo desses temas, embora existam diversos estudos isolados, pouco tem sido estudado e produzido em relação às localidades receptivas do turismo e seus atores.

Diante dessa situação, faz-se necessário estabelecer um elo entre os stakeholders e as estratégias utilizadas, de um lado, e, de outro, as localidades receptivas de turismo organizadas sob a forma de circuitos e, ou, consórcios.

Assim, o problema básico que a pesquisa enfocará é expresso da seguinte maneira: De que forma se processa a inserção e o envolvimento dos stakeholders nas estratégias existentes na atividade do turismo, congregadas nos circuitos e/ou consócios municipais?

O artigo está estruturado inicialmente com os aspectos do contexto da pesquisa bem como sua situação científica problematizadora, os aspectos teórico-conceituais de stakeholders e turismo que embasam o estudo, além da descrição dos procedimentos metodológicos adotados para se efetivar, sobretudo, a pesquisa de campo, e a apresentação, análise e interpretação dos resultados conjuntos da pesquisa e suas posteriores considerações finais a que chegou o estudo.

\section{Pressupostos Teórico-Conceituais}

Nos últimos 18 anos, os temas stakeholders e strategy têm sido abordados conjuntamente por diversos trabaIhos na literatura mundial. Nesse contexto, aparecem sob diversos aspectos, tais como: Análise dos stakeholders (HARVEY, 20 I I; SHIREY, 20 I 2); Gestão de stakeholders (MADSEN; ULHØI; ROOME, 200I; MCVEA, 2005); Influência de stakeholders (HENRIQUES; SHARMA, 2005; BREMMERS; OMTA; KEMP; HAVERKAMP, 2007); Integração de stakeholders (PLAZA -ÚBEDA; BURGOS-JIMÉNEZ; VAZQUEZ; LISTON-HEYES, 2009); Interação e relação dos stakeholders (ONKILA, 20I I); Interesse (JACOBS, 1997); Moralidade e Estratégia na identificação dos stakeholders 
(KALER, 2002); Participação dos stakeholders (GREEN; HUNTON-CLARKE, 2003); Reputação corporativa (MAHON, 2002); Responsabilidade Corporativa e Identidade (HEIKKURINEN; KETOLA, 20I2), Stakeholders intervenientes (POLONSKY; SCOTT, 2005); Percepção de stakeholders e estratégias de benchmarking (LACITY; HIRSCHHEIM, 1995); Teoria de stakeholders (POLONSKY, I995; KNOX; GRUAR, 2007; MINOJA, 20I2).

Especificamente, quando a preocupação se refere à inserção e o envolvimento de stakeholders na estratégia de organizações e regiões, se depara, na literatura mundial, com alguns trabalhos que versam sobre envolvimento (FLETCHER, 2007; VÉLAZ; SISON; FONTRODONA, 2007; CARDSKADDEN; LOBER, 1998); compromisso e engajamento (RODRIGUEZ-MELO; MANSOURI, 20II; SPRENGEL; BUSCH, 20I I; HADDOCK-FRASER; TOURELLE, 20I0), e compromisso e colaboração (BENDELL; COLLINS; ROPER, 20I0).

Quanto à participação e envolvimento, existem estudos que enfatizam a definição dos stakeholders, o sequenciamento, a forma e o propósito do envolvimento, e a coerência da participação (FLETCHER, 2007), o grau de identificação dos stakeholders a partir de seu envolvimento e participação nos objetivos estratégicos e na diferenciação organizacional (VÉLAZ; SISON; FONTRODONA, 2007) e a influência dos programas ambientais das organizações sobre o relacionamento com seus stakeholders-chave e os consequentes benefícios empresariais advindos com essa iniciativa (CARDSKADDEN; LOBER, 1998).

Por sua vez, o compromisso e engajamento dos stakeholders são vistos como crescente fator determinante da cons- cientização dos gestores empresariais na implementação de normas sustentáveis, de modo a fazer com que estas se tornem atraentes para os clientes das organizações (RODRIGUEZ-MELO; MANSOURI, 20II), estudados como fonte de pressão na escolha de estratégias (SPRENGEL; BUSCH, 20II).

No que se refere ao compromisso e a colaboração dos stakeholders, há estudo relacionado ao engajamento colaborativo, considerando as alianças estratégicas intersetoriais voltadas ao desenvolvimento sustentável, considerando obstáculos, desafios, tipos de desenvolvimento, formas de sociedade e tradições culturais (BENDELL; COLLINS; ROPER, 20I0).

$\mathrm{Na}$ medida em que se enfatiza a atividade do turismo, os stakeholders, especificamente, se constituem em um importante fator que influencia as organizações em um ambiente de complexas e rápidas mudanças e seu significado dentro de um contexto de eventos negativos é bastante subjetivo, em função de algumas peculiaridades que dependem da distância e do tipo do produto (GLAESSER, 2003).

Quando se avalia em nível prescritivo e numa dimensão que vai de uma organização até uma localidade ou região, outros aspectos merecem destaque no contexto entre stakeholder e estratégia. Nessa dimensão, o processo de formulação de estratégias para os stakeholders que se centram em: levantamento e descrição do comportamento dos stakeholders; coalizões possíveis; avaliação das forças estratégicas; ações específicas para os stakeholders; e integração dos stakeholders (FREEMAN, 1984). Tais aspectos se fazem importantes para a efetivação de uma junção entre o processo de planejamento estratégico de uma localidade com 
os seus stakeholders (comunidade), que não fazem formalmente parte da gestão pública da cidade. Esse processo desencadeia uma agenda de ações que envolvem a cidade, frente aos interesses daqueles que são colaboradores atuais e em potencial (AGRANOFF; MCGUIRE, 2003).

Quanto à inserção dos grupos de interesse no planejamento e nas organizações, novos parâmetros devem ser considerados. Se o planejamento tem a intenção de representar os pontos de vista de todos os stakeholders, então deveria ser óbvio que ele não seria automaticamente unânime $e$ homogêneo em termos de valores e visões (MASON (2003). De outra forma, tem-se o argumento de que a abordagem dos stakeholders, na definição dos objetivos de uma firma, se baseia no reconhecimento de que o negócio de uma organização é uma instituição social perseguindo interesses de múltiplos grupos (GRANT, 1998). Na teoria dos stakeholders, preconiza-se que os objetivos de uma organização são determinados pelas forças relativas dos vários grupos de influência envolvidos (EVANS, 2003), evidenciando a complexidade nas organizações e localidades no que tange aos seus desafios e destinações.

Os tipos detalhados de adequação que caracterizam o comportamento dos stakeholders devem ser subdivididos nas seguintes categorias: motivações e premissas; recursos disponíveis (material, simbólico, físico, status, habilidade); obrigações de caráter legal e de outros tipos; relacionamentos com outros stakeholders (MITROFF, 1983),

Murphy e Murphy (2004, p. 192) relatam que a adequada compreensão das motivações, necessidades e recursos dos stakeholders são essenciais para a formulação de estratégias e planos para o turismo. Preconizam que os objetivos de cada grupo sejam descritos no sentido de se isolar seus interesses-chave; em seguida, que deve ser realizado um exame de suas necessidades; e que se deve enfatizar a pertinência e o potencial efetivo de sua gestão, ligando-a com o planejamento estratégico dos negócios do turismo.

No que tange ao modelo teórico, Mitchell, Agle e Wood (1997) defendem a proposição de um modelo sustentado em três atributos: poder, legitimidade e urgência. Friedman e Miles (2006) descrevem que o modelo de saliência dos stakeholders inclui o poder de negociação dos stakeholders, a legitimidade no relacionamento com a organização e a urgência no atendimento às suas solicitações.As três dimensões de Mitchell,Agle eWood (1997) podem ser assim descritas: Poder - refere-se à posse ou obtenção de recursos coercitivos, utilitários e, ou, simbólicos como forma de imposição em relação a uma organização; Legitimidade - pode ser descrita como uma percepção generalizada ou suposição de que as ações de uma entidade são desejáveis, apropriadas ou adequadas dentro de algum sistema socialmente construído de normas, valores, crenças; Urgência - permite mover o modelo do estático para uma situação dinâmica, utilizando o termo como sinônimo de algo que é convincente, "driving" (condutor) (MITCHELL;AGLE;WOOD, 1997).

Robson e Robson (1996) descrevem como a gestão dos stakeholders pode ser implementada pelas organizações e suas implicações. Relatam algumas evidências empíricas em relação à inserção desses grupos no planejamento do turismo, discutindo uma perspectiva sobre o seu potencial, no sentido, de ajudar na manutenção 
do equilíbrio entre as atividades turísticas e as questões sociais e meio-ambientais.

Butler e Waldbrook (2003, p. 25-36), ao estudar planejamento do turismo com base nos recursos naturais, incorporam uma estrutura contemplando diversos fatores como acessibilidade, características da infraestrutura do turismo, grau de interação social, outras vantagens não utilizadas e a aceitabilidade dos impactos dos visitantes. Ao analisarem a interação social, os autores apontam que há a possibilidade de alterações nas áreas turísticas considerando o número de turistas/visitantes, ocasionando sua degradação.

Por fim, merecem destaque as contribuições de Calori, Baden-Fuller e Hunt (2000, p. 785), que estudam o gerenciamento das mudanças na cadeia hoteleira Novotel, enfatizando os aspectos diversos de atores, como a necessidade dos clientes, novas competências e habilidades dos empregados e obtenção de apoio dos stakeholders externos para transformações em grande escala e os seus custos financeiros implícitos.

\section{Procedimentos Metodológicos}

O trabalho realizado enquadra-se como sendo uma pesquisa do tipo exploratória, uma vez que se propôs a conhecer melhor e a delinear a inserção dos stakeholders nas estratégias existentes em localidades receptoras de turismo. Por sua vez, o caráter da pesquisa assume o método de investigação qualitativa, na medida em que se faz necessário o uso de informações sobre atores e processos interativos, maior profundidade dos dados resultantes e conteúdos mais ricos.

Em função da profundidade requerida, optou-se pelo método de estudo de caso, no formato de casos múltiplos, em que são analisadas as respostas em cada caso, seguido de comparações cruzadas e, por fim, da síntese das respostas de todos os participantes em torno de cada ponto investigado. Essa escolha se deu em função de as proposições do estudo não apontarem para a verificação de um fenômeno que tenha características singulares ou específicas, e de a pesquisa direcionar-se para um setor específico da atividade econômica, nesta pesquisa representada pelo turismo.

Quanto ao instrumento que conduziu as ações de pesquisa, foram adotados dois caminhos: (I) dedutivista, com procedimentos de campo que contêm informações sobre os casos investigados, procedimentos de coleta de dados e questões específicas; e (2) indutivista, a partir de que se podem chegar a algumas conclusões que ampliam o alcance do conhecimento trabalhado.

A população é dividida basicamente em três grandes categorias, quais sejam: (I) Pública - os municípios turísticos de São Paulo (SP), Natal (RN), Londrina (PR), Guarulhos (SP) e Atibaia (SP), representados pelos seus órgãos de governo da administração direta e indireta que contemplam o turismo em sua estrutura e, ou, ação. Tal escoIha se deve à questão de facilidade, acesso e disponibilidade de obtenção de dados e informações, tendo em comum o fenômeno da organização e gestão do turismo; (2) Privada - todas as atividades comerciais e, ou, produtivas, situadas no campo do turismo: meios de hospedagem, transporte, agenciamento e operação de viagens, empresas de city tour, casas de câmbio, etc.; (3) Comunitária - associações, conselhos, escolas e faculdades.

A opção referente à amostra pode ser caracterizada pelo tipo não probabilístico. 
Assim, busca-se essencialmente aprofundar o conhecimento, com a realização de um estudo de múltiplos casos em cinco municípios, com suas características complementares (capital de negócios, cidade turística e município do interior do Brasil), nos quais serão investigados stakeholders de três grandes grupos: (a) Grupo Público - Órgãos de governo local que tratam do turismo; (b) Grupo Privado - Empresas do setor e associações patronais de classe; e (3) Grupo Comunitário - Conselhos e associações locais de cunho comunitário. Em cada município,l escolheu-se um stakeholder representativo em cada um desses três grandes grupos (público, privado e comunitário). Trata-se de uma representação diversificada em localidades distintas, o que permite maior riqueza comparativa, com uma compreensão mais ampla do fenômeno estudado. No que se refere às etapas do processo de coleta de dados, a seguinte sequência foi observada: seleção dos casos, projeto do protocolo de coleta de dados, condução de cada estudo de caso e relatório de cada caso individual.

Em relação ao instrumento de coleta de dados, optou-se pela observação direta, por meio do uso da entrevista, a qual implica maior interação entre o pesquisador e os entrevistados, e em que a interferência do entrevistador é maior, na medida em que a comunicação interativa é conduzida e realizada. Desse modo, foi utilizada a entrevista semiestruturada e não disfarçada, aplicada pessoalmente pelos pesquisadores. Também, neste trabalho, foi usada a observação indireta, por meio da consulta bibliográfica e documental.

Quanto à análise e interpretação dos dados, seus significados e considerações, foram recombinadas as evidências encon- tradas, com o proposto teórico inicialmente apresentado. Operacionalmente, foram feitas análises comparativas entre os cinco municípios pesquisados, para cada um dos três grupos investigados (público, privado e comunitário). Depois, foram realizadas análises cruzadas e integradas entre os stakeholders de cada um dos municípios, de modo a verificar a articulação existente em cada região.

Nas análises realizadas, buscou-se verificar as semelhanças e os contrastes existentes em três dimensões: stakeholders, estratégias em localidades, e entre cada grupo pesquisado. Fez-se uso da técnica de análise de conteúdo, apropriada a estudos qualitativos dessa natureza, pois permite a análise das comunicações (quanti ou quali) e o conhecimento do que está por trás do texto, captando o conteúdo das mensagens, indicadores e conhecimentos relativos aos aspectos estabelecidos no estudo.

\section{Análise e Discussão dos Resultados}

Seguem-se, nesta seção, os resultados a partir do trabalho de campo (entrevistas) e da análise documental e seu conteúdo, a partir dos planos, programas ou projetos que esse setor tem utilizado para dimensionar ou desenvolver suas ações e captar recursos junto aos órgãos e níveis governamentais, financiadores da atividade econômica do turismo. Tomando por base o objetivo da pesquisa, os casos são analisados e discutidos, considerando-os individualmente (Natal, Atibaia, Guarulhos, Londrina e São Paulo) e conjuntamente.

Com relação às características dos stakeholders, no que diz respeito a seus interesses, poder de influência e atuação, primeira dimensão analisada, tornou-se essencial compreender a dinâmica dos stakeholders 
(interessados) e estabelecer suas estratégias diante do complexo fenômeno do turismo nas cinco localidades brasileiras, escolhidas como objeto desta pesquisa. Após longo esforço investigativo e ampla coleção de dados qualitativos, sobretudo, diversos aspectos são ressaltados e descritos revelando as dimensões da realidade empírica específica e global ou conjunta das localidades estudadas.

Apesar de as localidades estudadas desenvolverem o mesmo intento de crescerem e de se manterem competitivas, apresentam aspectos distintos ou peculiares em sua forma de integração e estratégia de ação, sobretudo nas duas vertentes principais e macro, tendo, de um lado, a intervenção e investimento do setor público, e, do outro, as empresas do setor e suas formas associativas. Tem-se como que um complexo jogo de interesses e influências, que vão desde a concepção dos propósitos e planejamentos, até as intervenções, ações diretas e busca de sua continuidade, o que nem sempre acontece, dadas as frequentes mudanças em nível governamental.

Trata-se de uma triangulação de atores que se identificam, atuam e influem na dinâmica do turismo nas localidades, e de uma triangulação analítica macro, contemplando as diversas cidades pesquisadas, verificando pontos comuns, concordantes, divergentes, aproximados, confrontados, comparados. Dessa forma, contempla-se, de modo mais amplo, a visão do turismo enquanto objeto de estudo nesta pesquisa, percebendo e buscando compreender um fenômeno complexo e multifacetado, além de sua característica inerente de interdisciplinaridade, uma vez que contempla áreas diversas de setores distintos. Uma trama de relações que requer tanto a percepção localizada como a compreensão macro, numa triangulação que procura convergir para um entendimento mais coerente da presença, influência e impactos dos stakeholders, suas articulações e estratégias traçadas para incrementar a atividade junto aos públicos de interesse e junto à comunidade e à sociedade.

As localidades estudadas, apesar de terem em comum o fenômeno do turismo, sua organização e desenvolvimento, fazem parte de regiões distintas, com realidades próprias, nas quais se insere a atividade turística. Natal, na região nordeste, apresenta uma forte presença do setor público na gestão e captação dos recursos para financiar e desenvolver a atividade, nas áreas de infraestrutura, capacitação, bem como em cultura e eventos. Em São Paulo, por sua vez, vê-se uma maior articulação das empresas do setor, na captação de eventos e formação e capacitação de recursos humanos, com o governo municipal atuando na criação e gestão de políticas públicas. Nesse contexto, destaca-se a busca de maior articulação através do Conselho Municipal de Turismo (COMTUR), dezenas de entidades, órgãos e instituições participantes.

Nesse caso, tem-se uma estrutura que se mantém e que acontece com certa regularidade, mas sem um poder de influência maior, uma vez que se tem limitado a ser um fórum de discussão, sem poder de decisão maior, não deliberativo. Acaba por ter um papel bastante restrito ao que se pressupunha que devesse ter, como órgão agregador de forças e agentes dos diversos mais diversos segmentos. Trata-se de um destino diferenciado de megacidade, onde as demandas e questões são multidimensionadas, o que, de alguma forma, se reflete na atividade do turismo e sua 
dificuldade de articulação maior na consecução das políticas e ações integradas que o município requer. Merecem destaque as entidades associativas em seus segmentos específicos, e, sobretudo, o de feiras e eventos, pelos quais a megacidade tem uma forte atração e tem priorizado como dinamizadores do turismo.

Outro aspecto que se pode ressaltar na articulação dos atores do turismo da megacidade de São Paulo refere-se à preocupação com os recursos ou valores humanos, em cursos de capacitação e formação, obtendo apoio financeiro de agentes federais do turismo (Embratur e Ministério), e do próprio municipal, além da participação das várias entidades diretamente interessadas e principais absorvedores e beneficiários das qualificações profissionais realizadas. Por isso, não se pode deixar de colocar em relevo a influência do megaevento Copa do Mundo, o que tem sido percebido e considerado, pelos agentes do turismo local, dentro do que mais se requer, que é a qualificação de mão de obra. Inclusive, apesar da grandiosidade da cidade, reconhece-se a carência de profissionais qualificados para atender a um público de megaeventos, suas demandas e exigências. Mesmo com uma maior autonomia pela grandeza do município, tem procurado obter recursos públicos para financiar ações turísticas, principalmente em capacitação e em infraestrutura.

Semelhantemente, no diferenciado município interiorano de Atibaia, tem-se a percepção e realidade da falta de mão de obra qualificada, o que leva a uma preocupação local por investir com certa prioridade nessa área, tendo forte participação da iniciativa privada do turismo e do nível governamental, local e estadual. Como nas outras cidades, em Atibaia questiona-se igualmente o papel do Conselho Municipal de Turismo que, de uma esperada função de gerenciamento macro da atividade no município, tem sido um espaço de comunicações informativas, atualizações de atividades a acontecerem na municipalidade, deixando de influenciar de forma mais deliberativa e decisiva. Ao órgão oficial local de turismo tem-se requerido a presença na dimensão da infraestrutura, em termos de investimento e manutenção, aspecto relevante para o tipo de turismo e demanda que se tem nessa localidade paulista. Dentre os aspectos que dificultam a captação de profissionais qualificados, essa localidade revelou-se o aspecto dos baixos salários, a que fizeram referência e que leva a um nível de desinteresse e desestímulo para a atuação na área do turismo. Todos se mostram unânimes quanto ao fato de os aspectos políticos municipais não se articularem suficientemente com o setor, como um todo, refletindo-se no papel da secretaria, restrito a ações específicas, segundo a demanda.

O Comtur, no município de Guarulhos, demonstra uma maior vitalidade, com regularidade de encontros e reuniões, com atuação destacada, mas, como outras localidades, sem maior poder de decisão deliberativa, apesar de relevante como interlocutor entre os diversos agentes públicos, privados e institucionais. Nessa localidade, tem-se a captação forte de recursos federais para investir em infraestrutura e capacitação, com a participação no Prodetur, o que requereu a elaboração do PDITS, por meio de consultoria contratada. Os atores articulam-se na realização de eventos, nacionais e internacionais, aproveitando o diferencial da presença do terminal inter- 
nacional de passageiros aéreos, o que se constitui num forte vetor para viabilizar a atividade turística. A continuada realização de conferências de turismo e a integração dos diversos atores têm sido oportunidade, inclusive, para elaboração de estratégias para a atividade turística local.

Também em Londrina, diferenciada como polo educacional de formação superior e técnica, o Comtur é problemático e chega a ser praticamente inativo, o que levou os atores locais à formação de um núcleo com espaço de convergência e à articulação de ideias para o desenvolvimento da atividade turística local. É relevante o papel da atividade de eventos, que congrega várias associações, as quais se arregimentam na dinamização desse segmento, no turismo local. Estruturalmente, o turismo é parte de uma diretoria maior, que se ocupa do desenvolvimento da cidade, sendo bastante citado, mas com baixa atuação efetiva no setor.

Dadas as características locais, tem-se evidenciado mais a atividade de eventos, com uma participação expressiva do convention bureau local, que congrega vários atores que pactuam no desenvolvimento, atração e realização de eventos.

Em relação às considerações da primeira dimensão analisada, tem-se que, apesar de se ter um conjunto de localidades turísticas pesquisado, e considerando sobretudo as especificidades e demandas distintas de cada uma, muitos aspectos foram comuns, mesmo numa nação continente como o Brasil. Apesar das distâncias consideráveis e das características próprias, em todas as localidades, praticamente, tem-se o esforço de priorizar o turismo como alternativa de desenvolvimento para os municípios. Nesse sentido, envi- dam os maiores esforços de planejamento e integração numa perspectiva estratégica, vislumbrando o curto e o longo prazo, e com a participação efetiva dos principais atores locais do turismo. Mesmo tendo que superar barreiras e entraves internos, conquistas foram efetivadas, e saídas foram encontradas para viabilizar o turismo, localmente. Se não foi possível por uma via esperada, no cumprimento dos objetivos e metas estabelecidos em planos estratégicos ou planos diretores do turismo, outras vias foram efetivadas pela iniciativa das diversas entidades locais atuantes no turismo, com destaque para os setores da hotelaria, que tem tido mais forte presença, bem como o setor de eventos, por meio dos Conventions e associações várias que atuam em áreas específicas do setor.

Não se pode negar a existência de problemas diversos, conflitos e tensões, em face da multiplicidade de visões que, muitas vezes, não se cruzam. Pelo contrário, se chocam ao ponto de inviabilizarem trabalhos longos e complexos de elaboração de planos, diretrizes e prioridades, ficando sem efetividade. Ressalta-se com isso o impacto maior da desarticulação, na maioria das vezes, entre o setor público municipal e os empresários da iniciativa privada, e os compromissos e exigências ambientais e sociais que delimitam muitas ações.

Apesar de serem esperados os desentendimento e incongruências, em geral não são aceitos ou digeridas facilmente, em face da potencialidade que $\circ$ turismo tem de angariar recursos e proporcionar ganhos em escala para os municípios, em termos sociais e econômicos. Os atores estão ativos, presentes e atuantes, e dispostos permanentemente a ações e políticas que possibilitem mudanças que tragam desen- 
volvimento, numa perspectiva sustentável, para as localidades. É evidente a superestima particular de entidades e grupos, em suas visões e interesses, e isso tem afetado a dinâmica do setor, em face do que já se poderia ter avançado, conforme previsto e acordado em planos e projetos. Isso aponta para uma busca permanente de melhorias e entendimentos, o que passa pela compreensão efetiva do papel de stakeholders de um setor competitivo e promissor econômico, social e ambientalmente.

Nos casos estudados, de alguma forma, pode-se verificar que os pressupostos de Freeman ( I984, p. I3I), para o processo de formulação de estratégias para os stakeholders, que se centram na análise/descrição de seu comportamento e estratégicas genéricas, são utilizados pelos atores em diferentes graus. Fica um pouco mais claro ao utilizarmos a estrutura de Mitroff (1983) quanto aos tipos detalhados de adequação, que caracterizam o comportamento dos stakeholders. Há certa clareza quanto as motivações dos stakeholders, os recursos impostos, conhecimentos específicos e opiniões, comprometimentos de ordem legal e seus desdobramentos. Tais fatos se coadunam com os dizeres de Murphy e Murphy (2004, p. 192), ao relatarem que o entendimento das posições, motivações, necessidades e recursos dos grupos de stakeholders são, antes de tudo, de valor incalculável para a formulação de estratégias para o turismo.

A segunda dimensão analisada é relativa às influências recebidas no processo de formulação, concepção e composição de estratégias turísticas, por parte dos stakeholders, e as formas como isto ocorreu. Pode-se perceber que a elaboração do Plano municipal de turismo, no caso de
São Paulo, por meio do Conselho e órgão local, constitui-se na influência maior, na medida em que tem uma forte abrangência, contemplando eixos básicos para o desenvolvimento na atividade turística. Isso passa pelo fortalecimento da integração da cadeia produtiva, informação e pesquisa, valorização da cultura, lazer e entretenimento, além do investimento na imagem da cidade mega. Embora intencione ser geral, acaba por ter um viés mais mercadológico, beneficiando a atividade privada e empreendedora do setor. Ao longo do processo, várias oportunidades de integração foram proporcionadas entre os atores locais, sobretudo as associações de classe. Mesmo assim, reclama-se da dificuldade de articulação em questões específicas e práticas, como a questão da sazonalidade, que provoca efeitos fortes na atividade. Uma vez que afeta a todos, era de se esperar que todos se articulassem, o que não tem ocorrido.Além disso, tem-se a necessidade de entendimento quanto à concentração das atividades e eventos, cuja preocupação não tem sido superada no megamunicípio de São Paulo.

A seu turno, os atores do turismo local de Guarulhos têm procurado se integrar na elaboração de diretrizes que orientem os muitos subsegmentos do turismo local. Mostram-se atentos a questões específicas, mas que têm influência na atividade do dia a dia, como é o caso do calendário inteligente, que foi considerado e destacado pelos participantes das reuniões e seminários. Vale salientar que, em tudo que o município estabelece como propósito estratégico, procura obedecer à base sustentável, como parâmetro necessário do turismo sustentável.

A elaboração de plano municipal de 
turismo praticamente centralizou as atenções no município de Atibaia, inclusive com orientação técnica externa, gerando um documento detalhado de todo o processo, ações, posicionamento e cenários esperados, com a participação de praticamente todos os atores, destacando-se o setor hoteleiro. Porém, não houve a implementação das ações, o que gera um sentimento de frustração e preocupação com o desenvolvimento da localidade. Até então, tudo caminhava de forma satisfatória, sendo afetado por influências política de gestão pública, suas mudanças e instabilidades, comprometendo um esforço tão válido e promissor, conforme estabelecido no plano diretor do turismo. O próprio conselho (COMTUR) não exerceu a influência necessária para incrementar as mudanças planejadas e almejadas. Ressalte-se o papel da rede hoteleira, como principal articulador, assumindo a frente e tendo iniciativas de diálogo, inclusive com partidos e governo, o que, mesmo diante disso, não garantiu a execução de ideias criteriosamente elaboradas.

Um fator que pode provocar uma maior influência estratégica refere-se à expectativa de apoio no megaevento Copa do Mundo, da Fifa, sobretudo em termos de meios de hospedagem, o que requer mão de obra qualificada, sendo esse um dos grandes desafios a serem alcançados, salientando sempre a questão da valorização do profissional, mesmo com salários ainda não atrativos. $O$ turismo local sente a ausência de integração maior, e mesmo a comunicação entre os stakeholders, para com isso viabilizar qualquer iniciativa exequível e viável para o município, como destino turístico. Há uma clara desarticulação, embora existam iniciativas isoladas, além de recursos turísticos potenciais ainda para se desenvolver.

Da mesma forma, em Londrina, teve-se a elaboração, embora de modo mais simples e objetivo, de um plano estratégico, inclusive com apoio técnico do Sebrae, utilizando técnicas estratégicas, mas com pouca efetividade, dada a influência e complicação burocrática do setor público, que comprometeu a sua plena execução. A presença mais forte, localmente, refere-se ao setor de eventos, por meio de suas entidades, com participação efetiva no planejamento estratégico. Estabeleceu, como uma das prioridades e principal demanda, a disposição de um espaço centro de convenções para a captação e realização de grandes eventos e desenvolvimento de mais essa área específica, capitaneando outros benefícios para o turismo local. Isso, no entanto, tem esbarrado na falta de visão local de turismo e a dificuldade de recursos financeiros. Tem-se ainda a possibilidade de submeter o projeto, diante da realização, no Brasil, do megaevento Olimpíadas, podendo ser utilizado como opção turística e realização de eventos. Ressente-se bastante, localmente, da falta de convergência das visões do setor público e do privado, do que dependem, praticamente, as principais ações estratégicas necessárias para desenvolver turisticamente o município.

Não parece ser diferente em Natal, um destino que galgou seu espaço no contexto do turismo nacional e internacional, tendo que superar dificuldades internas e de recursos. Para tanto, a estruturação do fórum regional, congregando municípios do litoral leste do estado, com sede na capital, Natal, é o divisor de águas, sobretudo no que diz respeito à obtenção de financiamentos públicos por meio do Prodetur, 
cujos recursos se transformaram em ações de infraestrutura necessárias. Destaque-se a ausência de burocracia e elaboração de documentos nesse formato de fórum, sendo agilizados compromissos e ações, além de comitês de estudo, para se chegar à definição de prioridades.

Também sofre influência política, com as mudanças nas gestões, o que afeta a efetividade do planejamento-ação do fórum regional. Merece destaque ainda a condição de ser uma das sedes da copa do mundo, o que tem centralizado todo plano e ação turísticos, diante do enorme desafio municipal e estadual de atender os requisitos e metas estabelecidos. Os atores locais contam assim com esse forte vetor, Copa do Mundo, para reerguer o turismo, que teve perdas, sobretudo no turismo internacional, nos últimos anos, por problemas locais e globais da economia mundial. Atualmente, continua-se na busca de execução do plano de desenvolvimento do turismo sustentável, prioridade para se manter como destino recebedor de recursos de financiamento para a atividade local e região litorânea de turismo.

No que tange às considerações da segunda dimensão analisada, observa-se que, se consideradas pelo porte, pela localização, pela distância física e geográfica, temse uma grande diferença entre as cinco localidades brasileiras pesquisadas e analisadas nessa pesquisa, o que de fato ocorre, até em termos de região sul, sudeste, nordeste. Nessa última, a presença do governo é acentuada como principal influenciador das ações no município que, aliás, é sempre considerado no plano da regionalidade litorânea a que pertence, que congrega vários municípios. Diferentemente, no sul e sudeste, as maiores cidades apresentam uma maior vitalidade no empresariado, como atores mais destacados na articulação de iniciativas, ações e mudanças necessárias para sobrevivência e desenvolvimento do setor turístico local. Com destaque, temse os setores de eventos e hotelaria como os stakeholders mais efetivos, algumas vezes trazendo para si a responsabilidades de algumas ações e medidas para incrementar a atividade turística e viabilizar a demanda de turistas nas respectivas localidades.

A visão de stakeholders permite compreender a dinâmica local do turismo, suas especificidades, sobretudo na perspectiva dos próprios atores que, por meio de suas percepções, e de documentos efetivados, configuram o desenho das complexas inter-relações necessárias para dinamizar, econômica e socialmente um setor, além da sua exigência ambiental. Um complicado jogo de interesses e influências se entrecruzam no cenário do turismo local, ora conflitantes ora efetivos de mudanças, em várias dimensões necessárias. É um esforço de superação permanente de busca de interesses particulares aliados a interesses coletivos e socialmente construídos, de forma a possibilitar mais benefícios do que problemas, em prol de uma atividade multifacetada de opções variadas e que condiz com cada realidade específica dos municípios.

Observou-se, nos casos estudados, que, assim como aponta Glaesser (2003), os stakeholders são um importante fator que influencia as organizações em um ambiente de complexas e rápidas mudanças. Faz-se necessária uma junção entre o processo de planejamento estratégico de uma localidade com os seus stakeholders (em nível da comunidade), que não fazem formalmente parte da gestão pública da cidade (AGRA- 
NOFF; MCGUIRE (2003)). Tal processo pode desencadear ações frente aos interesses dos stakeholders atuais e em potencial, como também alerta Mason (2003).

\section{Considerações Finais}

Visualizar e compreender as múltiplas articulações dos atores do complexo fenômeno do turismo, em suas lógicas locais, tornou-se possível na perspectiva da teoria dos stakeholders, que possibilita a identificação dos entrecruzamentos dos interesses, aliando a isso a dimensão estratégica, que cenariza, ativa e aponta para um horizonte mais amplo de futuro. Nesse contexto, pode-se afirmar que as articulações entre stakeholders locais ou municipais têm se efetivado, o que demonstra o crescimento do setor, apesar das dificuldades inerentes em todo processo de integrar organizações, instituições, grupos e setores distintos.

A identificação dos stakeholders e o nível de integração e interesses demonstram-se fortemente dinâmicos e complexos, para se conter em um estudo, mas foi possível um mapeamento das características e formas de articulação e seu enquadramento nas concepções teóricas e metodológicas do que pressupõem os autores, conceitos e modelos na área de stakeholders e estratégia. A teoria se mostra condizente como representação e previsão da realidade de fatos comuns, independentemente do setor com o qual se está trabalhando. Ora as corrobora, ora não corresponde às realidades específicas do turismo, nas localidades verificadas. Entretanto, foi possível utilizar os modelos teórico e metodológico para visualizar e compreender o fenômeno estudado.

Os stakeholders, em geral, caracterizamse por revelarem consciência do seu papel como parte interessada no processo turístico das localidades e fazem uso disso, em geral, para se beneficiarem diretamente ou para contribuírem para um processo mais amplo de lógica de setor. Nesse contexto, ocorrem tensões e embates, muitas vezes levando à ineficácia dos propósitos estabelecidos, o que acaba por comprometer, em parte, muitas ações que poderiam ser efetivadas e trazer ganhos econômicos e sociais para os municípios. $E$, dessa forma, colaborar com a dinâmica da busca do desenvolvimento do turismo em suas localidades e suas influências externas. Em geral são entidades, associações, empresários, setor público os mais destacados e presentes stakeholders do setor local do turismo, com menor presença da comunidade em geral. $O$ setor do turismo, em geral, requer uma maior e mais frequente presença e intercomunicação dos stakeholders, em face da forte interdependência de suas atividades. Daí a necessidade de se reunirem em diversos formatos: fóruns, planejamentos, busca de financiamentos, divulgação, qualificação, dentre outras prioridades da área. Com a realização próxima, dos megaeventos no Brasil, isso está requerendo um nível mais exigente e consistente de entendimento na somatória de esforços conjuntos para viabilizar projetos e ações que advêm de eventos desse porte.

Em termos de influência, trata-se de um aspecto que oscila, dependendo do momento em que se está, como na necessidade de elaboração de planos estratégico e diretor de turismo, locais, para o que todos são convocados a darem suas parcelas significativas de colaboração. São eficientes na concepção e criação de proposições, propostas e intenções, pertinentes e viáveis, mas encontram dificuldade em sua 
consecução, por dependerem de muitas decisões posteriores e prioridade de interesses junto aos órgãos públicos, sobretudo. Destaca-se a influência política como uma variável incontrolável nesse processo, que tem pesado negativamente quanto ao sucesso das investidas para incrementar o turismo nas localidades. Além disso, atuam os stakeholders de forma isolada em seu métier, procurando paralelamente envidar esforços e planos de ação estratégica que acabam trazendo influência para o restante dos segmentos do turismo local. De uma forma ou de outra, tem-se avançado, ficando certo nível de frustração por não se verem as propostas elaboradas implementadas totalmente e, às vezes, nem executadas.

Mesmo diante disso, trata-se de um aprendizado de articulação de interesses e estratégias que vão se conformando com o passar do tempo, nunca, no entanto, perdendo de vista a prioridade da atividade como um todo e as responsabilidades individuais, de cada ator, num processo mais amplo.

Como limitações, houve aspectos relacionados ao tempo, deslocamento e coincidência de agendamentos para a realização das entrevistas com os stakeholders de cada localidade, exigindo por vezes longos percursos. Alie-se a isso a dificuldade de relacionar as várias visões e percepções em um contexto analítico único, procurando pontos convergentes e coincidentes bem como aspectos que não corroboravam os pressupostos. Pode-se também incluir, como mais um dos aspectos restritivos, 0 volume de informações necessárias para atender aos objetivos da pesquisa, por meio dos instrumentos de pesquisa, considerando que foi necessário fazer ajustes ao longo do processo, sem perder de vista o foco nem comprometer a pesquisa em nada, o que requereu um bom esforço. Percebe-se a necessidade de continuidade, avançando na compreensão de aspectos que foram ressaltados e só possíveis com a realização da pesquisa in loco.

A partir deste estudo, apontam-se aspectos de continuidade e prosseguimento, numa temática que permite um escopo amplo, sobretudo no setor do turismo.Assim, pode ser identificada uma agenda de temáticas de estudos futuros, nessa perspectiva teórica e metodológica de stakeholders e estratégia. Podem ser elencados temas voltados para: TI - Stakeholders e sustentabilidade em destinos turísticos brasileiros; T2 - Stakeholders e articulações estratégicas em megaeventos; T3 - Influências de stakeholders na gestão pública de municípios turísticos;T4 - Stakeholders e regionalização do turismo;T5 - Stakeholders e cenários futuros para o turismo local e regional;T6 - Stakeholders, estratégia, governos e desenvolvimento; T7 - Papel estratégico dos stakeholders no planejamento e gestão do turismo municipal e regional; T8 - Articulação de stakeholders e comunidades locais no desenvolvimento do turismo local e regional.

Após um rigoroso e extensivo processo de realização, bem como o aprendizado com esse relevante estudo, pode afirmar que a presença e inserção dos stakeholders na concepção, consecução e efetivação dos planos e ações estratégicas torna-se determinante no processo de desenvolvimento, a partir do turismo, nos municípios, apesar dos conflitos e tensões para os quais sempre se encontram alternativas de solução, mesmo que sem uma maior abrangência e impactos positivos. É evidente que tudo isso traz comprometimentos em curto prazo, na medida 
em que gera frustrações a partir do esforço e qualidade das medidas e propósitos traçados.Apesar das dificuldades e incongruências da realidade turística quanto aos interesses e suas influências, trata-se, no entanto, de um aprendizado para o qual os stakeholders do segmento demonstram-se dispostos e conscientes, sobretudo diante das perspectivas potenciais e reais para um setor cada vez mais propositivo e competitivo nos cenários das economias locais e regionais.
Pode-se concluir que o processo de desenvolvimento do turismo, nos destinos locais, em especial, tem estreita relação com o papel dos diversos stakeholders institucionais, associativos e até pessoais, cuja perspectiva é preciso compreender, para alcançar melhor nível de desenvolvimento, na acepção da palavra, contemplando, simultânea e conjuntamente, as necessárias e prioritárias dimensões econômica, social e ambiental e competitiva. 


\section{REFERÊNCIAS}

AGRANOFF, Robert; MCGUIRE, Michael. Collaborative public management: New strategies for local governments. Washington, DC: Georgetown University Press, 2003.

BENDELL, Jem; COLLINS, Eva; ROPER, Juliet. Beyond Partnerism: Toward a More Expansive Research Agenda on Multi-Stakeholder Collaboration for Responsible Business. Business Strategy and the Environment, [S. I.], v. 19, p. 35I-355, 2010.

BREMMERS, Harry; OMTA, Onno; KEMP, Ron; HAVERKAMP, Derkjan. Do stakeholder groups influence environmental management system development in the Dutch agri-food sector? Business Strategy and the Environment, [S. I.], v. 16, p. 2|4-23।, 2007.

BUTLER, R. W.; WALDBROOK, L. A. A new planning tool: the tourism opportunity spectrum. The Journal of Tourism Studies, [S. I.], v. I4, n. I, p. 25-36, May 2003.

CALORI, Roland; BADEN-FULLER, Charles; HUNT, Brian. Managing change at Novotel: back to the future. Longe Range Planning, [S. I.], v. 33, p. 779-804, 2000. Disponível em: < $<w w$. periódicos.capes. gov.br> Acesso em: 0I fev. 2008.

CARDSKADDEN, H.; LOBER, D. J. Environmental stakeholder management as business strategy: the case of the corporate wildlife habitat enhancement programme. Journal of Environmental Management, [S. I.], v. 52, p. 183202, 1998.

CERTO, Samuel C.; PETER, J. P. Administração estratégica: planejamento e implantação da estratégia. 2. ed. São Paulo: Pearson / Prentice Hall, 2005.
EVANS, Nigel; CAMPBELL, David; STONEHOUSE, George. Strategic management for travel and tourism. Oxford, UK: Elsevier Butterworth Heinemann, 2003.

FLETCHER, S. Converting science to policy through stakeholder involvement: An analysis of the European Marine Directive. Marine Pollution Bulletin, [S. I.], v. 54, n.12, p. I88I-1886

FREEMAN, R. Edward. Strategic management: a stakeholder approach. Marshfield, MA: Pitman Publishing, 1984.

FRIEDMAN, Andrew L.; MILES, Samantha. Stakeholders: theory and practice. Oxford: Oxford University Press, 2006.

GLAESSER, Dirk. Crisis management in the tourism industry. Oxford: Butterworth-Heinemann, 2003.

GRANT, Robert M. Contemporary strategy analysis: concepts, techniques, applications. $3^{\text {rd }}$. ed. Malden: Blackwell, 1998.

GREEN,A. O.; HUNTON-CLARKE, L. A typology of stakeholder participation for company environmental decision-making. Business Strategy and Environment, [S. I.], v. I2, p. 292-299, 2003.

HADDOCK-FRASER, Janet Elaine; TOURELLE, Marielle. Corporate motivations for environmental sustainable development: exploring the role of consumers in stakeholder engagement. Business Strategy and the Environment, [S. I.], v. 19, p. 527-542, 2010.

HARVEY, Joan. A ratings-based stakeholder analysis for a food production company, including trust and risk implications. Business Strategy Series, [S. I.], v. I2, n. 3, p.
98-I04, 2011.

HEIKKURINEN, P.; KETOLA, T. Corporate Responsibility and Identity: from a stakeholder to an Awareness Approach. Business Strategy and the Environment, [S. I.], v. 2I, p. 326-337, 2012.

HENRIQUES, Irene; SHARMA, Sanjay. Pathways of stakeholder influence in the Canadian forestry industry. Business Strategy and the Environment, [S. I.], v. I4, p. 384398, 2005.

HENSHER, D. A.; BREWER, A. M. Developing a freight strategy: the use of a collaborative learning process to secure stakeholder input. Transport Policy, [S. I.], v.8, n. I, p.I-10, 200I.

JACOBS, M. The Environment as stakeholder. Business Strategy Review, [S. I.], v. 8, p. 25-28, 1997.

KALER, John. Morality and strategy in stakeholder identification. Journal of Business Ethics, [S. I.], v. 39, n. I, p. 91-100, 2002.

KNOX, Simon; GRUAR, Colin. The application of stakeholder theory to relationship marketing strategy development in a non-profit organization. Journal of Business Ethics, [S. I.], v. 75, n. 2, p. II5I35, 2007.

LACITY, Mary C.; HIRSCHHEIM, Rudy. Benchmarking as a strategy for managing conflicting stakeholder perceptions of information systems. Journal of Strategic Information Systems, [S. I.], v. 4, n. 2, p. 165-185, 1995.

MADSEN, Henning; ULHOI, John P. Integrating environmental and stakeholder management. Business Strategy and the Environment, [S. I.], v. 10, p. 77-88, 2001.

MAHON, John F. Corporate reputation: a research agenda using stra- 
tegy and stakeholder literature. Business and Society, [S. I.], v. 4I, n. 4, p. 4I5-445, Dec. 2002.

MASON, Peter. Tourism impacts, planning and management. Oxford, UK: Elsevier Butterworth Heinemann, 2003.

MCVEA, J. F. A names-and-faces approach to stakeholder management: how focusing on stakeholders as individuals can bring ethics and entrepreneurial strategy together. Journal of Management Inquiry, [S. I.], v. I4, n. I, P. 57-69, 2005.

MINOJA, Mario. Stakeholder management theory, firm strategy and ambidexterity. Journal of Business Ethics, [S. I.], v. 109, n. I, P. 67-82, 2012.

MITCHELL, R. K.;AGLE, B. R.;WOOD, D. J. Toward a theory of stakeholder identification and salience: defining the principle of who and what really counts. Academy of Management Review, [S. I.], v. 22, 1997.

MITROFF, Ian I.Stakeholders of the organizational mind: toward a new view of organizations policy making. San Francisco, CA: Jossey -Bass Publishers, 1983.
MURPHY, Peter E.; MURPHY, Ann E. Strategic management for tourism communities: bridging the gaps. Aspects of Tourism 16. Clevedon, UK: Channel View Publications, 2004.

ONKILA, Tiina. Multiple forms of stakeholder interaction in environmental management: business arguments regarding differences in stakeholder relationships. Business Strategy and the Environment, [S. I.], v. 20, p.379-393, $201 \mathrm{I}$.

PLAZA-ÚBEDA, J. A.; BURGOS-JlMÉNEZ, J.; VAZQUEZ, D. A.; LISTON-HEYES, C. The 'win-win' paradigm and stakeholder integration. Business Strategy and the Environment, [S. I.], v. I8, p.487-499, 2009.

POLONSKY, Michael Jay. A stakeholder theory approach to designing environmental marketing strategy. Journal of Business \& Industrial Marketing, [S. I.], v. 10, n. 3, p. 29-46, 1995.

POLONSKY, Michael Jay; SCOTT, Don. An empirical examination of the stakeholder strategy matrix. European Journal of Marketing, [S. I.], v. 39, n. 9-10, p. I I99-
I2I5, 2005.

ROBSON J.; ROBSON I. From shareholders to stakeholders: critical issues for tourism marketers. Tourism Management, [S. I.], v. I7, n. 7, p. 533-540, Nov. 1996.

RODRIGUEZ-MELO, A.; MANSOURI, S. A. Stakeholder engagement: Defining Strategic Advantage for Sustainable Construction. Business Strategy and the Environment, [S. I.], v. 20, p.539-552, 2011.

SHIREY, Maria R. stakeholder analysis and mapping as targeted communication strategy. The Journal of Nursing Administration, [S. I.], v. 42, n. 9, p. 399-403, 2012.

SPRENGEL, D. C.; BUSCH, T. Stakeholder engagement and environmental strategy: the case of climate change. Business Strategy and the Environment, [S. I.], v. 20, p.35I-364, 20II.

VÉLAZ, Iñaki; SISON Alejo José G.; FONTRODONA, Joan. Incorporating CSR and stakeholder management into corporate strategy: a case study of the CAN experience 2002-2006. Corporate Governance, [S. I.], v. 7, n. 4, p. 434-445, 2007. 